\title{
Comparison of colicine production and diffusion on different solid media
}

\author{
J. MCGEACHIE AND W. MCCORMICK \\ From the University Department of Bacteriology, Glasgow Royal Infirmary
}

SYNOPSIS Using a freezing-thawing method for extracting colicine from solid media it has been shown that the choice of media for production and diffusion is important. Digest nutrient agar yielded the most colicine and peptone water agar the least. A factor in bacteriological peptone, but absent in a proteose peptone (Difco) and Neopeptone, was responsible for inhibiting production on peptone water agar. Dextrose reduced the diffusion of colicine. A minimum of six hours' incubation of the colicinogenic organism was required for satisfactory production of colicine.

Several methods for demonstrating colicine production have been described since Gratia (1925) first reported the presence of an antibiotic substance produced by Esch. coli on solid media. Fredericq, Thibault, and Gratia (1946) described a stroke plate method which was subsequently modified by Shannon (1957). Chapple (1962) has described a method using electrophoresis. Halbert and Magnuson (1948) describe a method of extracting the colicine from solid media which we have developed to test the differences of colicine production and diffusion on several media.

\section{MATERIAL AND METHOD}

Petri dishes containing $20 \mathrm{ml}$. amounts of the following media were used:-

DIGEST NUTRIENT AGAR This was prepared from Hartley's broth as described by Mackie and McCartney (1960) with $1 \cdot 2 \%$ agar (May and Baker) added.

PEPTONE WATER AGAR This was prepared as described by Mackie and McCartney (1960) with $1.2 \%$ agar (May and Baker) added.

BLOOD AGAR BASE No. 2(OXOID) This contains $1 \cdot 2 \%$ agar no. 3 (Oxoid).

SENSITIVITY TEST AGAR(OXOID) This contains $1.2 \%$ Ionagar no. 2.

TRYPTONE SOYA AGAR(OXOID) This contains $1.5 \%$ agar no. 3.

Several batches of these media were compared to ensure that there was no variation between batches.

Received for publication 12 December 1962.
Tryptone soya (see Table 1) was the only medium to show variation between batches both in colicine production and diffusion.

The indicator organisms were the Shig. sonnei strains used by Abbott and Shannon (1958). The colicinogenic organism was an Esch. coli isolated from a case of pyelonephritis.

\section{METHOD OF COLICINE TESTING}

EXTRACTION The various media were inoculated with a standard loopful of a 24-hour nutrient broth culture of the organism to be tested for colicinogenic properties. The plates were incubated at $37^{\circ} \mathrm{C}$. for a variable time between two and 24 hours (Table II). Afterwards the organisms were killed by exposure to chloroform vapour for one hour. The plates were then frozen at $-15^{\circ} \mathrm{C}$. in a deep-freeze overnight and next morning they were removed and thawed. The fluid produced at the thawing, usually $10 \mathrm{ml}$., was centrifuged at 4,000 r.p.m. for 15 minutes and the supernatant was withdrawn and used for the tests.

TESTING OF EXTRACT A loopful of a 24-hour broth culture of the indicator organism was spread over the agar plates. Using a no. 4 cork borer $(8 \mathrm{~mm}$. in diameter) plugs of the inoculated agar were removed and the hole filled with five drops of the colicine extract. The drops were delivered from a Pasteur pipette which was not standardized. The amount of extract required to fill the hole was approximately $0.15 \mathrm{ml}$. The variation between the amounts was very slight, as a standard amount of agar $(20 \mathrm{ml}$.) and standard cork borer for each indicator plate were used. The plates were then incubated at $37^{\circ} \mathrm{C}$. and examined next morning.

The diameters of the zones of inhibition were measured and recorded.

The extracts have been retained at $-10^{\circ} \mathrm{C}$. for more than 12 months and have not deteriorated in this time. 
RESULTS

EFFECT OF THE MEDIUM ON COLICINE PRODUCTION The comparison of colicine production on different media is shown in Table I. It will be noted that digest nutrient agar (E1) gave the largest zones of inhibition on all diffusion media tested. Peptone water agar (E2) did not produce recordable amounts of colicine.

EFFECT OF MEDIUM ON DIFFUSION The comparison of colicine diffusion in different media is also shown in Table I. Diffusion occurred best on peptone water agar. On sensitivity agar (Oxoid) diffusion was poor. Resistant variants developed within the zones of inhibition on Sensitivity test agar, blood agar base no. 2, and in both batches of tryptone soya agar.

TIME FOR ADEQUATE COLICINE PRODUCTION Table II and Fig. 1 demonstrate the colicine produced on digest nutrient agar at various time intervals. Peptone water agar was used for diffusion. Adequate colicine was produced after six hours at $37^{\circ} \mathrm{C}$. and there was little difference in the amount of colicine produced after 14 hours' incubation.

EFFECT OF PEPTONE ON PRODUCTION OF COLICINE To test the effect of peptone on production $0.5 \%, 1.0 \%$, and $2.0 \%$ bacteriological peptone (Oxoid) was added to digest nutrient agar. The zones of inhibition were decreased from the 'peptone-free' control of $21 \mathrm{~mm}$. to $10 \mathrm{~mm}$. with the $0.5 \%, 9 \mathrm{~mm}$. with the $1 \%$, and no inhibition with the $2 \%$, extracts.

A comparison of other commercial peptones was made. Table III shows the zones of inhibition pro-

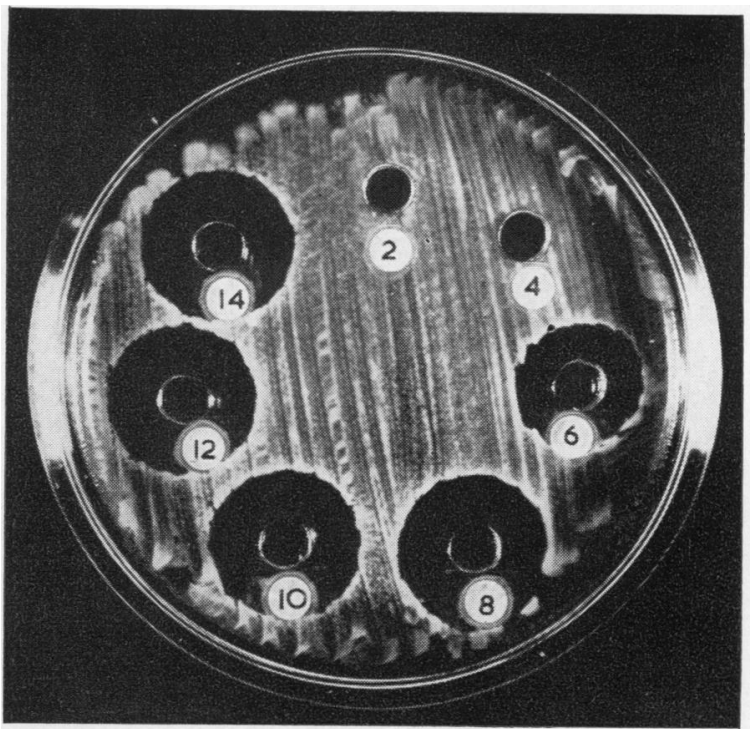

FIG. 1. Zones of inhibition produced by colicine extracts from digest agar cultures incubated for two to 14 hours.

duced by the extracts from digest nutrient agar plates to which were added $1 \%$ of the various peptones.

THE EFFECT OF DEXTROSE ON DIFFUSION Dextrose, in concentrations of $0.5 \%, 1 \%$, and $2 \%$, was added to the peptone water agar plates and the diffusion of the digest agar extract was reduced from a control of $21 \mathrm{~mm}$. to $17 \mathrm{~mm}$. at all three concentrations.

TABLE I

COMPARISON OF COLICINE PRODUCTION AND DIFFUSION IN DIFFERENT MEDIA

Colicine Extract Diffusion Media

Digest Peptone Water 'Sensitivity Test' Blood Agar Base Tryptone Soya (I) Tryptone Soya (2) No. 2

\begin{tabular}{|c|c|c|c|c|c|c|}
\hline E1 & $21 \mathrm{~mm}$. & $21 \mathrm{~mm}$. & $15 \mathrm{~mm} .(\mathrm{R})$ & $20 \mathrm{~mm}$. (R) & $20 \mathrm{~mm}$. (R) & $20 \mathrm{~mm}$. (R) \\
\hline E2 & - & - & - & - & - & - \\
\hline E3 & $10 \mathrm{~mm}$. & $16 \mathrm{~mm}$. & - & $9 \mathrm{~mm}$. & $10 \mathrm{~mm} .(\mathrm{R})$ & $15 \mathrm{~mm}$. (R) \\
\hline E4 & $10 \mathrm{~mm}$. & $16 \mathrm{~mm}$. & - & - & $10 \mathrm{~mm}$. & $14 \mathrm{~mm}$. (R) \\
\hline E5 & - & $11 \mathrm{~mm}$. & - & - & - & $10 \mathrm{~mm}$. \\
\hline E6 & - & $9 \mathrm{~mm}$. & - & - & - & - \\
\hline
\end{tabular}

E1, E2, E3, E4, E5, E6, are extracts from digest nutrient agar, peptone water agar, 'sensitivity test' agar, blood agar base no. 2 agar, batch I and batch II, tryptone soya agar respectively

(R) = colonies of resistant variants developed within 24 hours

- $=$ no zone of inhibition.

TABLE II

COMPARISON OF INCUBATION TIME AND COLICINE PRODUCTION Incubation Time in Hours

\begin{tabular}{|c|c|c|c|c|c|c|c|c|c|c|c|c|}
\hline & & & & & & & & & & & & \\
\hline & 2 & 4 & 6 & 8 & 10 & 12 & 14 & 16 & 18 & 20 & 22 & 24 \\
\hline Diameter of inhibition ( $\mathrm{mm}$.) & 0 & 0 & 18 & 20 & 20 & 20 & 21 & 21 & 21 & 21 & 21 & 21 \\
\hline
\end{tabular}


TABLE III

COMPARISON OF EFFECT OF VARIOUS PEPTONES ON COLICINE PRODUCTION

Medium

'Peptone-free' control

Bacteriological peptone (Oxoid) $1 \%$

Bacteriological peptone (Evans) $1 \%$

Mycological peptone (Oxoid) $1 \%$

Proteose no. 3 peptone (Difco) $1 \%$

Neopeptone (Difco) $1 \%$

\section{DISCUSSION}

The method we have described is simple to perform in a routine laboratory. There is no technical difficulty as in the electrophoretic method of Chapple (1962). The colicine pattern of organisms may be obtained within 48 hours of isolation and there is adequate extract remaining to act as a control for further investigation on different batches of media. The number of extracts which can be tested varies with the size of the cork borer; using the number 4 we have found that 10 strains can be tested on each indicator plate.

The extraction of colicine from solid media has enabled us to study some of the factors causing variation in colicine production and diffusion. The addition of bacteriological peptone to the digest nutrient agar inhibited production markedly. This could explain why no recordable colicine was produced on peptone water agar. The other commercial media tested also contain peptones: these were a proteose peptone or, in the case of tryptone soya agar, soya peptone. From our investigation op the various peptones it would appear that there is factor present in the bacteriological peptone but: absent in proteose (Difco) and Neopeptone which prevents or reduces colicine production. So far we have been unable to define this factor.

The inhibition of diffusion by dextrose has beene suggested before by Blackford, Parr, and Robbin $\$$ (1951) and we have confirmed their findings. The poor diffusion on sensitivity agar may thus be due to the $1 \%$ dextrose which it contains.

As we have demonstrated, the choice of medium used for production and diffusion is important $\omega$ Routinely we prefer to use digest nutrient agar fo the production and peptone water agar for testing. the inhibition of indicator organisms. Digese nutrient agar may be used for both procedures, but there is the possibility of missing some of the weak colicines.

We should like to thank Dr. J. C. J. Ives for his encourage ment, Dr. R. R. Gillies for supplying the indicator strain of Shig. sonnei, and Mr. T. Parker for the photograph.

\section{REFERENCES}

Abbott, J. D., and Shannon, R. (1958). J. clin. Path., 11, 71. Blackford, V. L., Parr, L. W., and Robbins, M. L. (1951). Antibiotics $1,392$.

Chapple, P. J. (1962). J. clin. Path., 15, 484.

Fredericq, P., Thibault, J., and Gratia, A. (1946). C.R. Soc. Biol: (Paris), 140, 1035

Gratia, A. (1925). Ibid., 93, 1040.

Halbert, S. P., and Magnuson. H. J. (1948). J. Immunol., 58, 397.

Mackie, T. J., and McCartney, J. E. (1960). Handbook of Bacteriology 10 th ed. Livingstone, Edinburgh.

Shannon, R. (1957). J. med. Lab. Technol., 14, 199. 